\title{
Habitat selection by booming bitterns Botaurus stellaris in French Mediterranean reed-beds
}

\author{
Brigitte Poulin, Gaëtan Lefebvre and Raphaël Mathevet
}

\begin{abstract}
Data on habitat requirements of the threatened Eurasian bittern Botaurus stellaris are largely qualitative and limited to countries holding small populations. We assessed the habitat spectrum exploited by male bitterns during the breeding season, based on the analysis of 40 booming sites and 33 non-booming sites in 2,500 ha of heterogeneous reed-beds in the Camargue, France. Environmental variables contributing to booming site selection were, in decreasing order of importance, determined by their contribution to multivariate statistical models: water level in April, proportion of open water, density of dry and green reeds, percentage cover of non-reed species, salinity and turbidity of surface water, and reed height and diameter. Overall,
\end{abstract}

booming sites were characterized by a homogeneous cover of relatively sparse green and dry reeds growing with other plant species in shallow $(10-15 \mathrm{~cm})$, clear water. Because these findings are contrary to the traditional perception of bittern habitat in Europe, a reassessment of the species' ecological requirements throughout its distributional range is warranted. In the Camargue the main factors involved in habitat selection (water level and dry reed density) are directly associated with site management, and bitterns respond rapidly to slight environmental changes.

Keywords Booming bitterns, Botaurus stellaris, breeding, Camargue, France, Phragmites australis, reed harvesting, water management.

\section{Introduction}

The Eurasian bittern Botaurus stellaris is a species of high priority concern in Europe (Tucker \& Heath, 1994), especially in western Europe where most populations are less than a few hundreds of individuals (Kushland \& Hafner, 2000). Available information on the habitat requirements of this secretive bird is mostly qualitative and limited to areas holding small, isolated populations (Bibby \& Lunn, 1982; Tyler, 1992; Hawke \& Jose, 1996). Comparative analyses of sites occupied and unoccupied by bitterns in the UK (Tyler et al., 1998) and the Netherlands (De Kroon, 2001), has highlighted the importance of relatively large, wet reed-beds at an early stage of the hydroseral process for the conservation of the species. Habitat selection at a finer scale within extended reed-beds holding large bittern populations has not, however, been addressed.

The Rhone delta (Camargue) in Mediterranean France comprises $>8,000$ ha of reed-beds and holds about half the French bittern population (Rocamora \& YeatmanBerthelot, 1999). These reed-beds can cover hundreds of

Brigitte Poulin (Corresponding author), Gaëtan Lefebvre and Raphaël Mathevet* Station Biologique de la Tour du Valat, Le Sambuc, 13200 Arles, France. E-mail poulin@tourduvalat.org

*Current address: Centre d'Ecologie Fonctionnelle et Evolutive, CNRS UMR 5175, 1919 route de Mende, 34293 Montpellier Cedex 5, France.

Received 11 March 2004. Revision requested 25 August 2004. Accepted 13 April 2005 hectares and have suffered little change over the last few decades, except for an intensification of management practices to favour socio-economic activities such as waterfowl hunting and reed harvesting (Mathevet, 2001; Mathevet \& Mesléard, 2002). The topographic gradient from the water inland, together with the heterogeneity of management practices and their associated water levels, offer a broad gradient of environmental conditions from which to assess the habitat spectrum exploited by bitterns during the breeding season. By comparing water management and vegetation structure at sites used and unused for booming, we attempt to determine the primary factors involved in booming site selection and how these are compatible with the various socioeconomic activities carried out at the sites.

\section{Study area}

Data were collected at the Marais du Vigueirat in 2001, and at the Charnier- Scamandre in 2001 and 2002, in the Camargue, Mediterranean France (Fig. 1). The 980 ha Marais du Vigueirat is a nature reserve containing six reed-bed units totalling $275 \mathrm{ha}$. These units are of varying size (26-63 ha), age (reed area is still expanding in some units), and floristic composition. They are generally flooded throughout spring and most of the summer. All beds have reed Phragmites australis dominated vegetation that has not been cut during the last 15 years. Charnier-Scamandre comprises three brackish ponds 


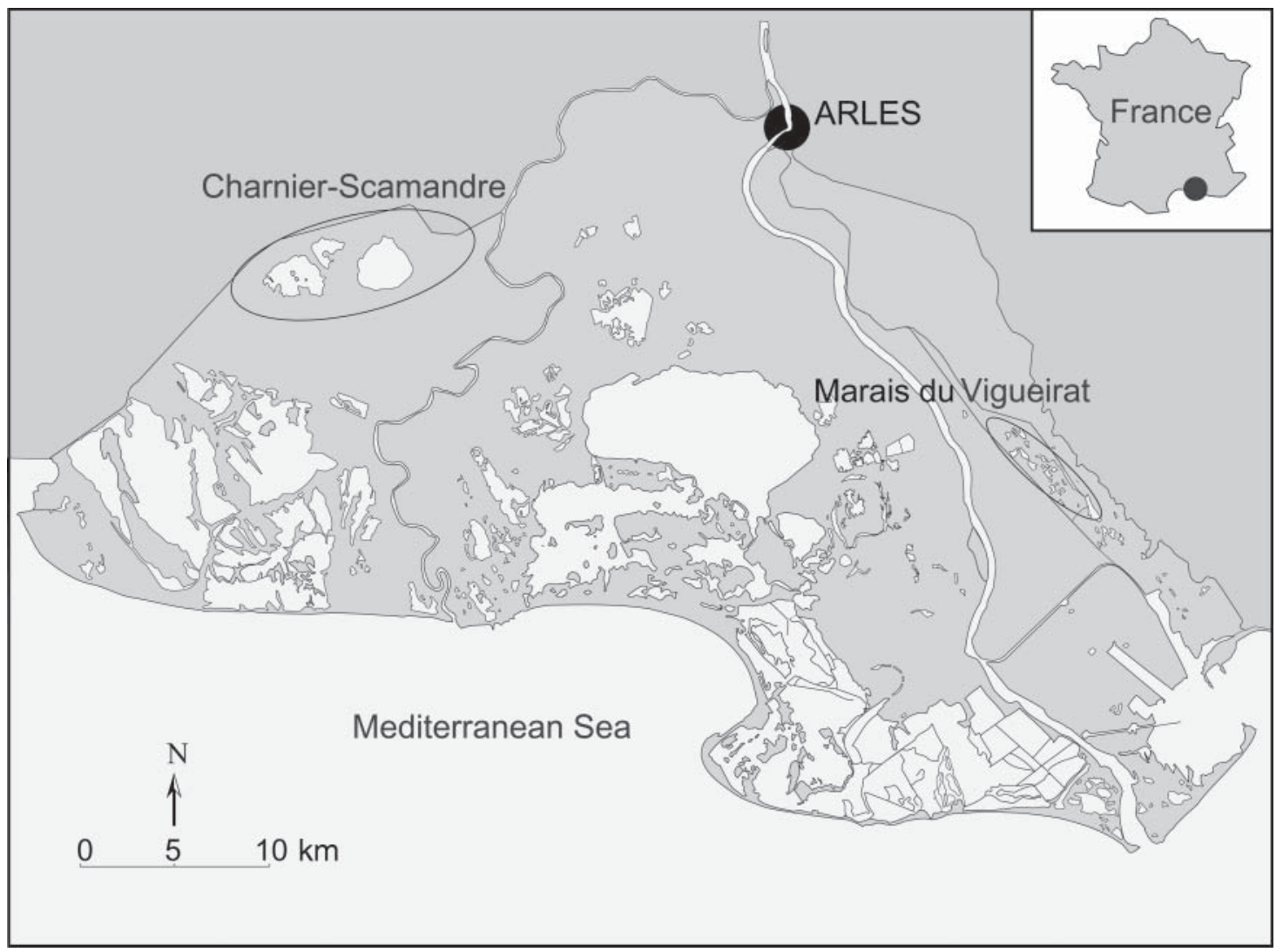

Fig. 1 Location of the two study sites, Charnier-Scamandre and Marais du Vigueirat, in the Camargue. The inset indicates the position of the main map in southern France.

totalling 1,240 ha surrounded by 2,270 ha of reeds. The reed marshes are divided into 37 hydrological units by a network of channels and dykes, allowing independent water management of single or grouped units. During the two winters of the study period 29 and 28 units were cut partially or totally, totalling $813(36 \%)$ and $777(34 \%)$ ha of cut reeds, respectively. Eight units were exploited for waterfowl hunting in autumn/winter of each year, totalling 511 ha $(23 \%)$. These two activities are seasonally compatible, but they are associated with different water level management (Mathevet et al., 2003). Water level in cut reed-beds is generally lowered twice a year, once in late summer to improve soil oxygenation and nutrient uptake, and once during the winter months to facilitate access and reduce the impact of cutting machines on the rhizomes. Reed-beds used for hunting are permanently flooded or drained once in spring after the hunting season.

\section{Methods}

\section{Bittern sampling}

Counts of booming males were carried out in late April during the period of maximum booming activity, i.e. during the 2 hours preceding sunrise (Poulin \& Lefebvre, 2003b). At Charnier-Scamandre and Marais du Vigueirat, respectively, 102 and 35 point counts of $2 * 10$ minutes were carried out every 300-400 $\mathrm{m}$ along dykes surrounding reed-beds. Overall, 54 and 49 males were counted at Charnier-Scamandre in 2001 and 2002, and 12 males at Marais du Vigueirat in 2001. The positions of these males were fixed by acoustic triangulation (Lefebvre \& Poulin, 2003). For each booming male eight directional bearings of their calls, on average, were taken from six different observer positions. These bearings were further integrated into a mathematical model using Andrews estimator to calculate a $95 \%$ probabilistic area enclosing the bittern position (White \& Garrott, 1990). The radius of these was 11-536 $\mathrm{m}($ mean $=109 \mathrm{~m})$.

\section{Selection of booming and non-booming points}

We chose a case-control design, in which booming and non-booming points were analysed with logistic regression (Keating \& Cherry, 2004). To ensure representative coverage one point was sampled in every hydrological unit each year. Whether it was a booming versus a non-booming point was decided based on the density of 
booming males within the unit (above or below average, respectively). Booming points corresponded to the most accurate bittern position (radius 11-69 $\mathrm{m}$, mean = $38 \mathrm{~m}$ ) within the hydrological unit, whereas non-booming points were selected arbitrarily within potential bittern habitat (large ponds, dykes and roads were excluded) and at least $250 \mathrm{~m}$ away from any bittern position. Based on these selection criteria, 34 booming points and 32 non-booming points were sampled at CharnierScamandre in both years. Booming points did not overlap spatially between years, but because bittern positions differed between 2001 and 2002, the same hydrological unit could hold a booming point in one year and a nonbooming point in the other year. At Marais du Vigueirat 6 booming points were sampled in 2001. Only one nonbooming point could be sampled because of the small area of accessible reed-beds (few sites $>250 \mathrm{~m}$ from a bittern location). Overall, nine hydrological units could not be sampled, either to avoid disturbance of Purple heron colonies (two units at Marais du Vigueirat) or because access was not allowed (seven units at Charnier Scamandre). These units included a wide range of bittern densities (0-0.81 per 10 ha) with an average value similar to accessible units ( 0.21 vs 0.36$)$ and their exclusion from our analyses is unlikely to have created a bias. The exact location of non-booming points at both sites was not decided in the field but from aerial photographs integrated into a Geographical Information System. These coordinates, as well as those of booming points, were located in the field using a Global Positioning System accurate to $4 \mathrm{~m}$.

\section{Sampling of water level and vegetation structure}

Water and vegetation sampling were carried out between 28 May and 14 June in 2001 and 2002. From a ladder at the centre of each booming and non-booming point, we estimated within a $40-\mathrm{m}$ radius the percentage of open water within $10 \%$ interval classes. Diameter and height of one green and one dry reed stem were measured along with water depth at the centre of the plot and at 10, 20, 30 and $40 \mathrm{~m}$ from the centre in each cardinal direction $(n=17)$. The stems selected for measurements were the closest to a $50-\mathrm{m}$ measuring tape attached to the centre of the plot. Density of green and dry reed stems, as well as the number of plant species other than reed and their percent coverage were estimated within $50 * 50 \mathrm{~cm}$ quadrats located at the centre of the plot, and at 15 and $35 \mathrm{~m}$ from the centre in each cardinal direction $(n=8)$. This sampling effort was defined based on the variability of the parameters measured by Poulin et al. (2002). Water turbidity and salinity were measured at the centre of each point. Water turbidity corresponds to the height of the water column needed to obscure a black
$X$ at the bottom of an EX76340s tube from ELE International (Leighton Buzzard, UK). Water salinity $\left(\mathrm{g} \mathrm{L}^{-1}\right)$ was extrapolated from water conductivity $\left(\mathrm{mS} \mathrm{m}^{-1}\right)$ measured with a conductivity meter. Water levels have been monitored fortnightly in each hydrological unit at both sites since April 2001 with a network of piezometers. A measure taken at the corresponding piezometer during the point sampling allowed us to further transform the water levels measured in late May or June (or later should the unit be dry then) into the water level of late April, when the bittern positions were determined.

\section{Statistical analyses}

We calculated a correlation matrix to examine interdependence between the measured environmental variables. The variables retained for further analyses were: water depth in April, density of green and dry reeds, height of green reed, basal diameter of dry reed, percent cover of species other than reed, proportion of open water within a $40-\mathrm{m}$ radius, water turbidity and water salinity. To identify which variables were involved in booming site selection by bitterns, we performed Generalized Linear Models (GLM), with a binomial distribution and a logit link function as habitat sampling was made a posteriori (McCullagh \& Nelder, 1999). Site and year were also included as variables in the model. Model selection was based on Akaike Information Criteria (AIC; Akaike, 1973). Statistical significance of parameter estimates was computed with a likelihoodratio $\chi^{2}$ test. To identify the relative contribution of each variable in booming site selection we used the weighted average of parameter estimates (Johnson \& Omland, 2004), which corresponds to the probability of a variable being selected in the best model. Only models within 2 units of the AIC of the best model were used for this analysis (Burnham \& Anderson, 2002).

We used standardized residuals of likelihood $\chi^{2}$ tests (Everitt, 1992) to compare the distribution value of each environmental variable at booming and non-booming sites. Environmental parameters of each hydrological unit were compared between the 2 years of sampling with $t$-tests for dependent samples when applicable (water level, turbidity and conductivity) and $t$-tests for independent samples otherwise.

To estimate the impact of human use, one-way ANOVA was used to compare bittern densities among hydrological units experiencing various management regimes. Each unit was assigned to one of four management categories: hunting, reed cutting, unmanaged and nature conservation. Hunting units were specifically managed to attract waterfowl and could have their reeds cut after the hunting season. Reed cutting units were managed for reed harvesting and had 20-100\% 
(mean $=77 \%$ ) of their total area cut the preceding winter. Unmanaged units were generally located on public estates suffering from conflicts among users for access to land and water. Nature conservation management aims to provide favourable habitat for reedbed birds. These units did not experience any hunting or reed cutting. A Fisher LSD post-hoc test was further used to identify which management practice yielded a significant difference in bittern density. All statistical analyses were performed with Statistica v. 6, (Statsoft, Tulsa, USA).

\section{Results}

\section{Best model}

The best model $\left(\chi^{2}=19.12, \mathrm{df}=4, \mathrm{P}=0.0007\right)$ involved four variables: water level in April, dry reed density, $\%$ cover of non-reed plants, and proportion of open water. Of these, only the proportion of open water was negatively related to bittern presence. As a result of the interdependence among variables (Table 1) thirty-three significant models $(\mathrm{P}<0.0018)$ were within 2 AIC units of the best model. Because these models can be considered as nearly equally useful (Burnham \& Anderson, 2002) in describing bittern preferences, we discuss each variable individually and use their probability of being selected in the best model (weighted average of parameter estimates) as an indicator of their relative contribution to booming site selection (Fig. 2), instead of restricting data interpretation to the best model.

\section{Influence of each environmental variable}

\section{Water levels and quality}

Water level was $0-30 \mathrm{~cm}$, with booming sites being distributed normally within this range (Fig. 3); it was selected in all 33 models. The analysis of standardized residuals revealed that bitterns had a preference for areas with $10-15 \mathrm{~cm}$ of water, and that they avoided dry areas. Water turbidity had a $21 \%$ probability of being selected in the best model. Distribution of booming and nonbooming sites was regular across turbidity values except for the clearest waters corresponding to $60 \mathrm{~cm}(<6$ Jackson Turbidity Units) where booming points were significantly more frequent than non-booming points. Water salinity had an $18 \%$ probability of being selected in the best model. Booming site distribution did not differ from that of non-booming sites across the salinity gradient. Booming points tended to be more numerous where salinity was lowest $(\mathrm{P}=0.0537)$, but some booming sites were located in areas with high salinity values.

\section{Vegetation structure}

Density of dry reed had a $58 \%$ probability of being selected in the best model. Overall, the number of dry stems were 0-103 within $50 * 50 \mathrm{~cm}$ quadrats. Distribution of booming and non-booming points were similar and both skewed to the left, except for the 41-60 class that was significantly more frequent among booming than non-booming points. The percentage of booming sites was nevertheless higher in the 1-20 density class (44 vs $26 \%$ ), which was also the best represented among the non-booming points. Density of green reeds had a $45 \%$ probability of being selected in the best model. It was 12-117 stems, with the distribution of booming points skewed to the left, and that of non-booming points skewed to the right. Bitterns showed a preference for the 31-45 density class, and avoided the 61-75 density class.

The percentage of open water and percentage cover of non-reed species had, respectively, a 54 and $48 \%$ probability of being selected in the best model. Non-booming sites were distributed normally according to open water, whereas booming points showed no trend. Although there was no consistent pattern between presence of bitterns and percentage of open water, bitterns showed a significant preference for areas with no open water. In regard to the percentage cover of non-reed species, booming points and non-booming points had a similar distribution, with the $0-10 \%$ class being the most important. Height of growing reed and dry reed diameter had a 3\% probability of being selected in the best model. Booming and non-booming sites were both normally distributed according to these two variables. However,

Table 1 Correlation matrix of environmental variables measured at booming sites.

\begin{tabular}{|c|c|c|c|c|c|c|c|c|}
\hline & $\begin{array}{l}\text { Water } \\
\text { salinity }\end{array}$ & $\begin{array}{l}\text { Open } \\
\text { water }\end{array}$ & $\begin{array}{l}\text { Green reed } \\
\text { density }\end{array}$ & $\begin{array}{l}\text { Dry reed } \\
\text { density }\end{array}$ & $\begin{array}{l}\% \text { plant } \\
\text { cover }\end{array}$ & $\begin{array}{l}\text { Green reed } \\
\text { height }\end{array}$ & $\begin{array}{l}\text { Dry reed } \\
\text { diameter }\end{array}$ & $\begin{array}{l}\text { Water level } \\
\text { in April }\end{array}$ \\
\hline Water turbidity & -0.425 & -0.007 & -0.367 & 0.215 & 0.165 & 0.306 & 0.153 & 0.251 \\
\hline Water salinity & & 0.094 & 0.415 & -0.165 & -0.238 & -0.238 & -0.159 & -0.065 \\
\hline Open water & & & -0.003 & 0.129 & -0.214 & -0.330 & -0.057 & 0.166 \\
\hline Green reed density & & & & -0.391 & -0.347 & -0.182 & -0.109 & -0.040 \\
\hline Dry reed density & & & & & -0.125 & 0.285 & -0.159 & 0.141 \\
\hline$\%$ plant cover & & & & & & -0.113 & 0.243 & -0.472 \\
\hline Green reed height & & & & & & & 0.040 & 0.260 \\
\hline Dry reed diameter & & & & & & & & -0.036 \\
\hline
\end{tabular}




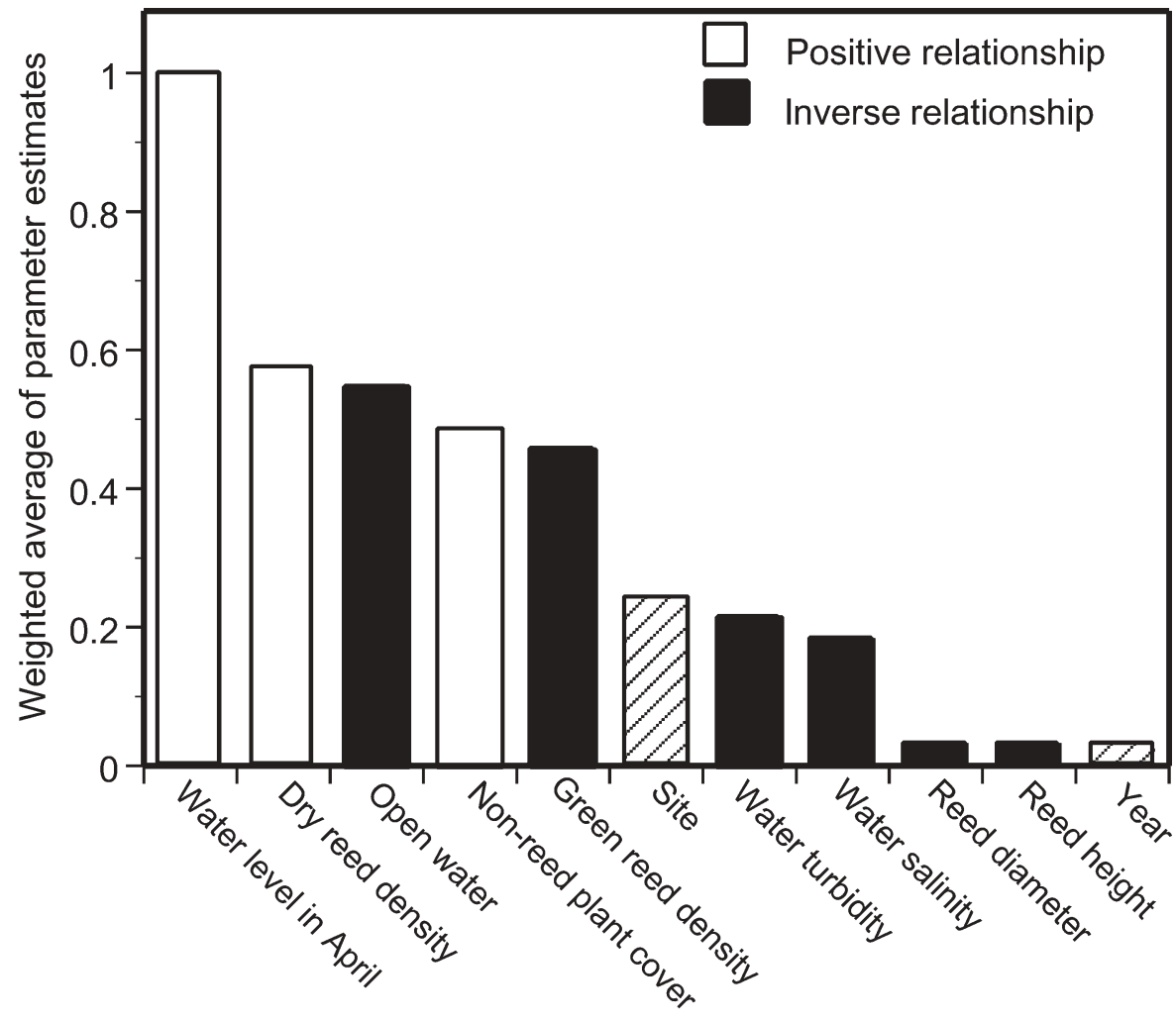

Selected factors
Fig. 2 Probability of each environmental variable being selected in the best model discriminating booming from non-booming points. distribution of reed height at booming sites was skewed to the right relative to that of non-booming sites, suggesting that bitterns show some preference for sites with higher reeds.

\section{Between-year and site differences}

Site and year had a minor impact, with 24 and 3\% probabilities of being selected in the best model, respectively. Nevertheless, the location of booming sites differed between 2001 and 2002 at Charnier-Scamandre (Fig. 4). All environmental variables showed similar values between years, with the exception of water level and reed height (Table 2). Considering that reed height has little influence on booming site selection (Fig. 3), these changes are probably related to water levels. Although the overall mean water level was $5 \mathrm{~cm}$ lower in 2002, three units experienced increases in water level of $>5 \mathrm{~cm}$ from 2001 to 2002, and the number of booming males in these units increased concurrently from 6 to 18 (Fig. 4).

\section{Bittern density relative to management practices}

Bittern density differed significantly among units in relation to their management goals (ANOVA $F=3.12$, $\mathrm{df}=3 \& 76, \mathrm{P}=0.031$ ). A decreasing pattern of booming male density was observed from nature conservation to reed cutting, hunting, and unmanaged units (Fig. 5). Bittern density in nature conservation units did not differ from densities associated with other management regimes, due in part to the less intensive management of nature areas that results in greater environmental variability. Bittern densities, however, were significantly higher in cut units than in unmanaged and hunted units (Fisher LSD, $\mathrm{P}<0.05)$.

\section{Discussion}

The bittern is highly eclectic in its ecological habits across Europe. It has been reported to breed in ricefields (Alessandria et al., 2003), saw-sedge (Puglisi et al., 2003), reed mace (Gauckler \& Kraus, 1965), and bulrush beds (L. Puglisi, pers. comm.), but is more commonly associated with old and wet reedbeds interrupted by water pools or canals where the intermingled dry culms offer a perch to feed at the water edge (Cramp \& Simmons, 1977; Bibby \& Lunn, 1982; Voisin, 1991). Within the range of conditions available at our study sites, bitterns did not select the wettest and oldest part of the reedbeds, nor did they show a preference for densely vegetated areas interrupted by water openings. Water level and reed density did play a major role, but atypically compared to previous reports (Voisin, 1971; Bibby \& Lunn, 1982; 

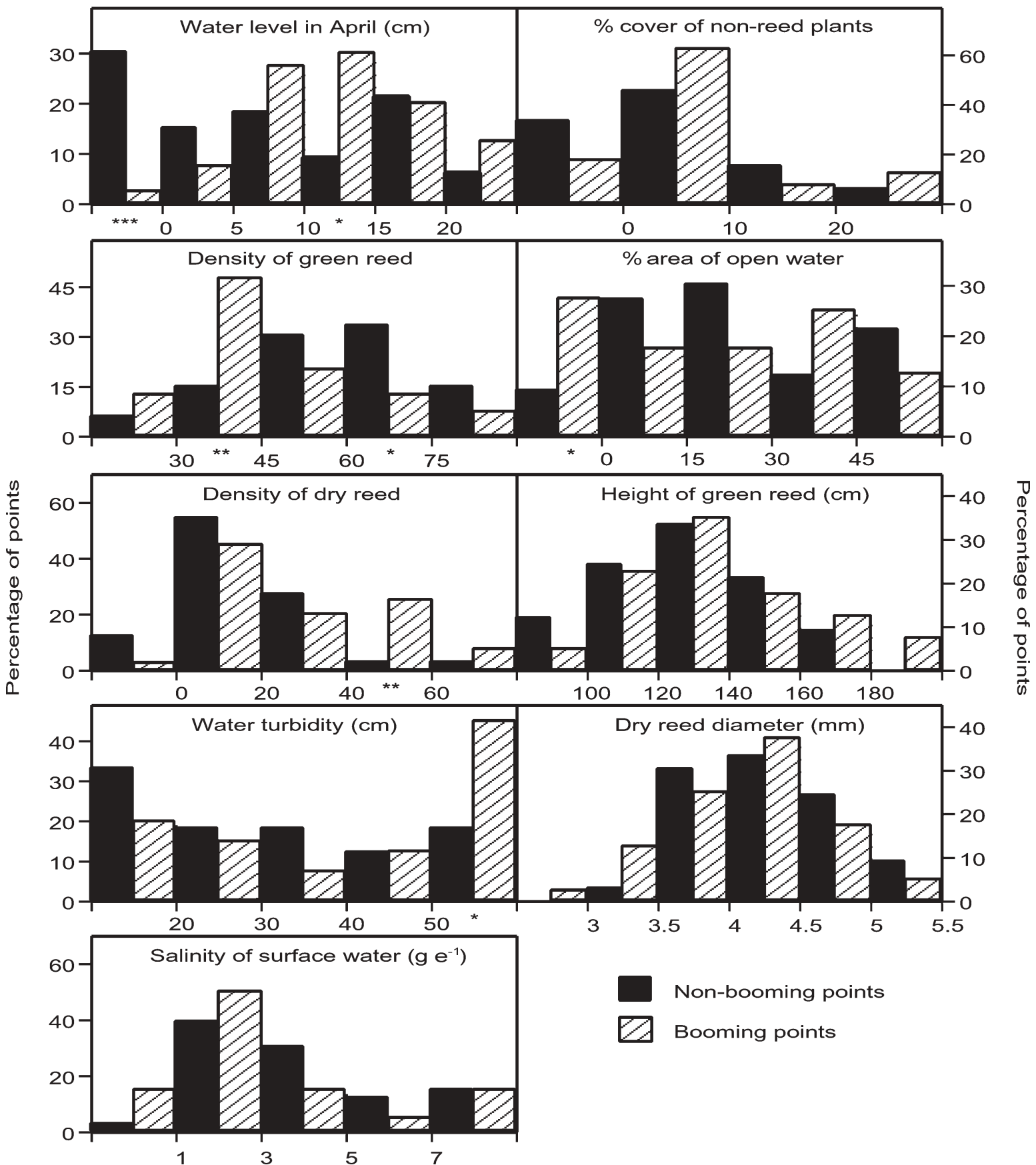

Non-booming points

$\angle$ Booming points

Fig. 3 Distribution of booming points relative to non-booming points for each environmental variable. Significant differences are indicated by asterisks ( $\left.{ }^{*} \mathrm{P}<0.05,{ }^{* *} \mathrm{P}<0.01,{ }^{* * *} \mathrm{P}<0.001\right)$.

Hawke \& Jose, 1996; Tyler et al., 1998; De Kroon, 2001). Booming sites were characterized by a homogeneous cover of relatively sparse green and dry reeds growing with other plant species in shallow, clear waters. These findings suggest that bitterns in the Camargue forage by walking on the ground amongst reed stems instead of trampling on the dense vegetation to reach water pools for feeding. This behaviour is favoured by reed harvesting management practices, which in addition to producing a low vegetation density, provides a compacted ground as a result of the summer drainage that permits the mineralization of organic matter.

The relatively low contribution of water turbidity and salinity to habitat selection suggests that feeding 


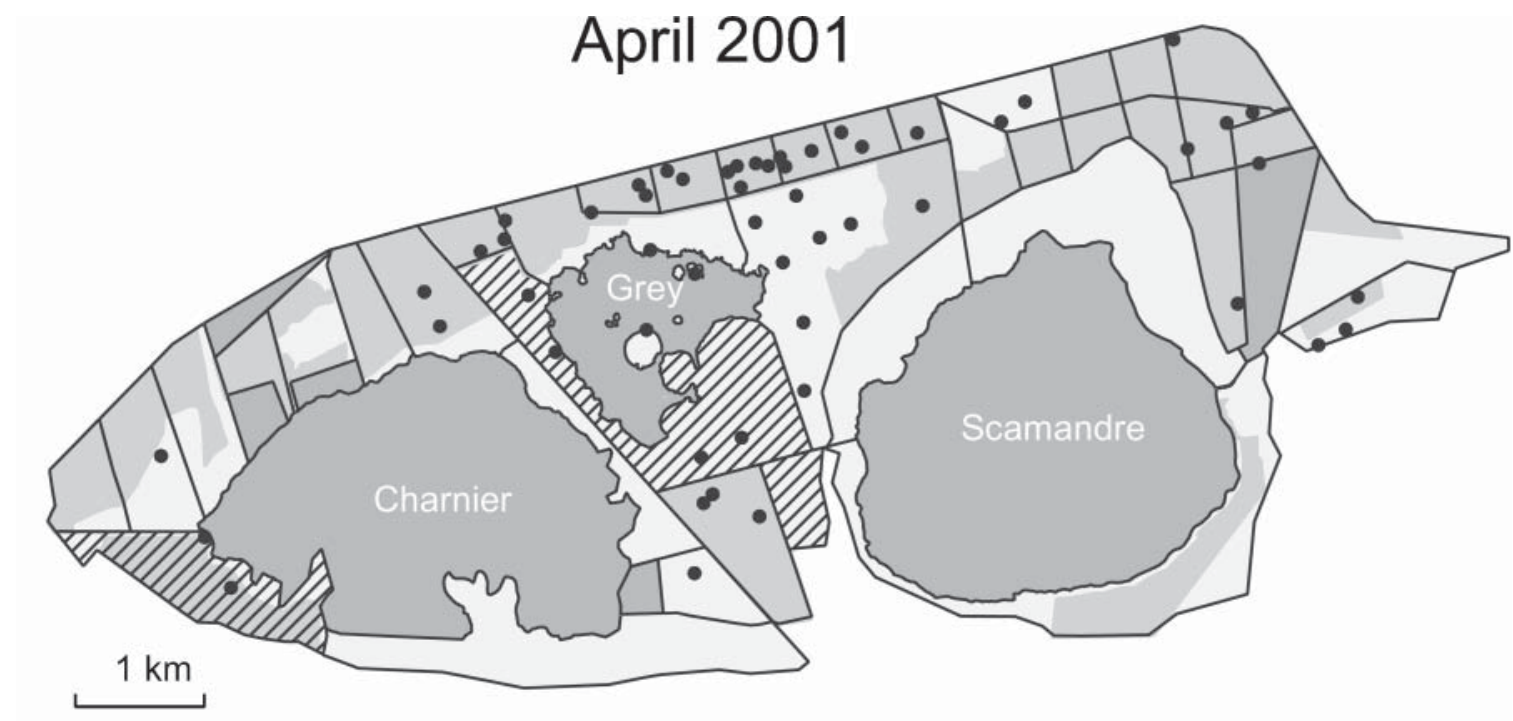
Uncut reed-bed Cut reed-bed Open water

- Booming male

Areas with increased water level in 2002

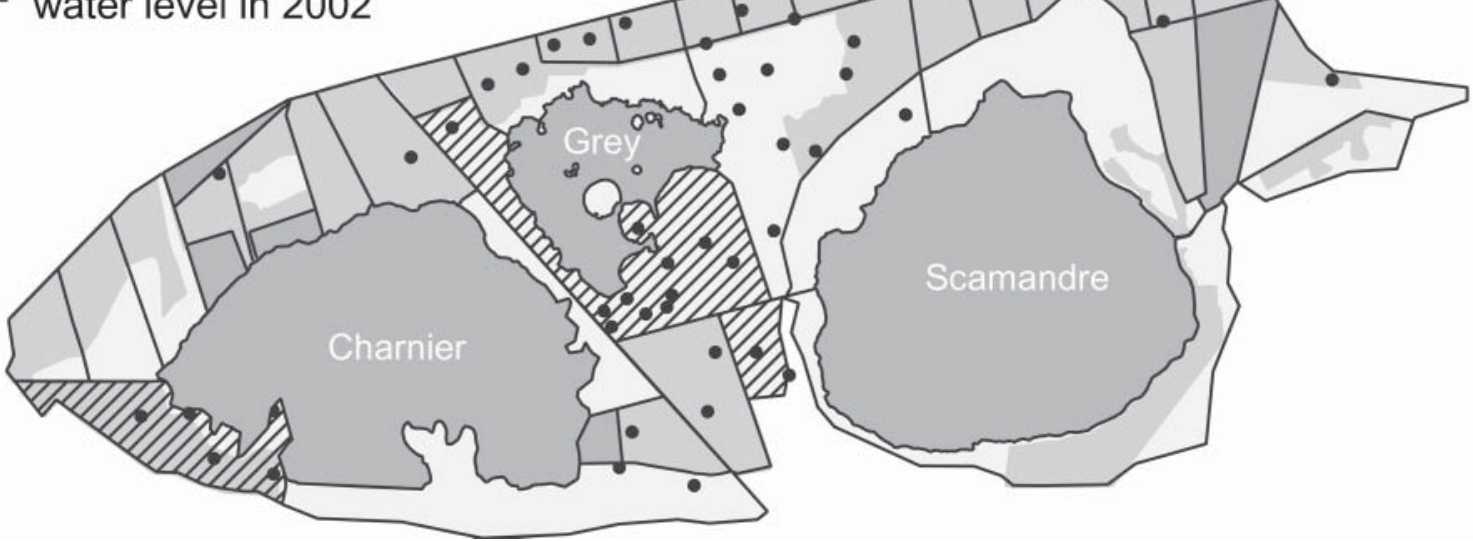

Fig. 4 Distribution of male bitterns in 2001 and 2002 at Charnier-Scamandre. Hatched areas experienced a water level increase from 2001 to 2002.

Table 2 Comparison of means between 2001 and 2002 for each environmental variable contributing to booming site selection at Charnier-Scamandre.

\begin{tabular}{|c|c|c|c|c|c|}
\hline Environmental variable & Mean 2000 & Mean 2001 & $t$-value & $\mathrm{df}$ & $\mathrm{P}$ \\
\hline \multicolumn{6}{|c|}{$t$-tests for equal variances } \\
\hline Water salinity & 5.57 & 7.19 & -1.55 & 71 & 0.1252 \\
\hline Open water & 21.82 & 28.24 & -1.40 & 71 & 0.1661 \\
\hline Green reed density & 51.64 & 51.72 & -0.02 & 71 & 0.9863 \\
\hline Dry reed density & 23.49 & 16.05 & 1.48 & 71 & 0.1436 \\
\hline$\%$ plant cover & 5.41 & 9.51 & -1.35 & 71 & 0.1806 \\
\hline Green reed height & 143.48 & 120.14 & 4.29 & 71 & 0.0000 \\
\hline Dry reed diameter & 4.47 & 4.29 & 0.76 & 71 & 0.4493 \\
\hline \multicolumn{6}{|l|}{ Paired $t$-tests } \\
\hline Watel level & 12.48 & 7.12 & 2.40 & 34 & 0.0218 \\
\hline Water salinity & 4.54 & 5.03 & -0.84 & 34 & 0.4078 \\
\hline Water turbidity & 39.69 & 34.37 & 1.22 & 31 & 0.2310 \\
\hline
\end{tabular}




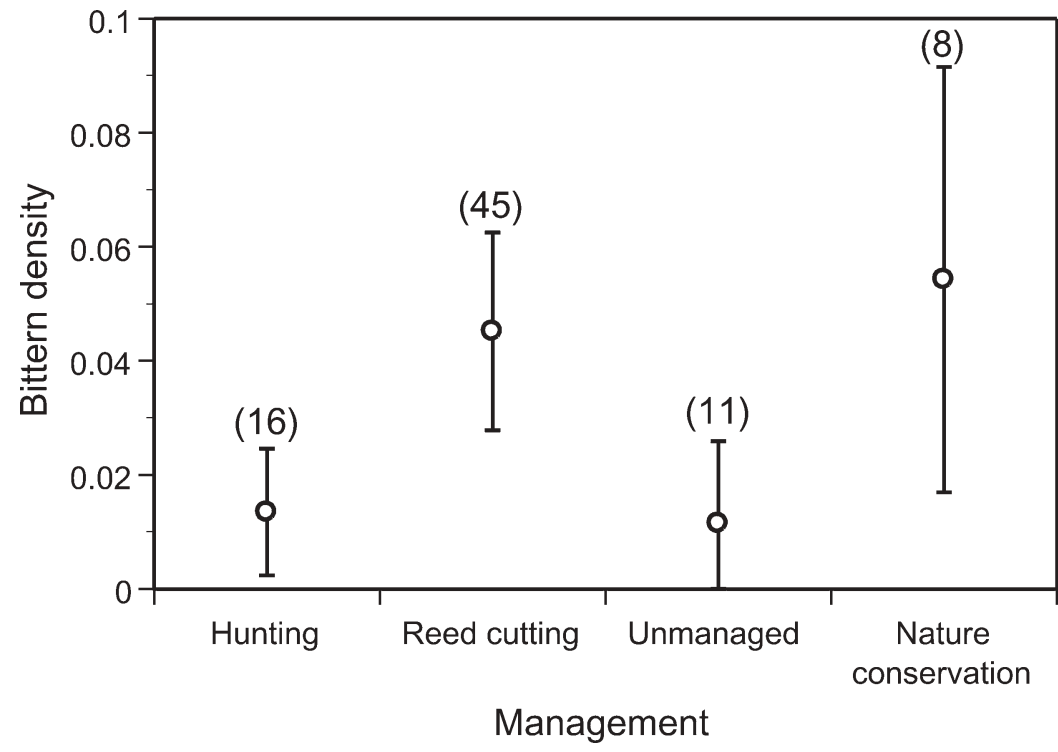

Fig. 5 Mean bittern density (number of booming males per ha, with $95 \%$ confidence intervals) in relation to management practices. Numbers in parenthesis refer to the number of hydrological units in both years combined. opportunities are relatively good throughout the study sites. Because bitterns are visual predators, water turbidity is expected to influence prey detectability, although it probably has little effect in shallow waters. Water salinity is expected to influence habitat selection primarily through its influence on the abundance and diversity of aquatic prey. The analysis of regurgitates and pellets collected at nests suggests the invasive red swamp crayfish Procambarus clarkii, a typical freshwater species, is a major food source for bitterns in the Camargue (Poulin, Lefebvre \& Crivelli, unpubl. data).

Reed height and diameter had little influence on booming site selection. In the Netherlands only tall and thick reeds are considered suitable for bitterns because they can support perching birds and their nests in deep water marshes (De Kroon, 2001). Although the salt present in many Camargue marshes produce a thinner reed than elsewhere in Europe, this is not limiting because of the local adaptation of bitterns to forage and nest on the ground.

Nearly $60 \%$ of the booming sites at the CharnierScamandre were located in areas cut the preceding winter. Few quantitative data exist on the relationships between bittern and reed harvesting. Winter cutting is generally considered beneficial in the mid-term by contributing to maintain habitat at a favourable hydroseral stage, but negative in the short-term because it provides insufficient vegetation cover for feeding and nesting activities in the following spring (Bibby \& Lunn, 1982; Tyler, 1992; Ward, 1992; Hawke \& Jose, 1996). Scrub encroachment resulting from litter accumulation is uncommon in Mediterranean France and reed harvesting at Charnier-Scamandre is purely of commercial interest.
The Mediterranean climate and artificial water management both favour early growth of reed in spring, which may in part explain the suitability of cut reed-beds to bitterns early in the breeding season. However, many booming sites located in cut areas contained a few culms of dry reed, demonstrating that a low density of dry stems is preferable to no dry reed at all. An ongoing experiment mixing patches of cut and uncut reeds at Charnier-Scamandre is confirming the importance of one-year dry culms in selection of nesting and booming sites (B. Poulin \& G. Lefebvre, unpubl. data). With a bittern density similar to that of reed-bed managed for bird conservation, reed cutting is certainly the socioeconomic activity most compatible with bittern requirements at our study sites. Although hunting management appears to be detrimental to male bitterns during the breeding season, it probably plays an important complementary role on a seasonal basis by providing a flooded habitat in winter when most harvested reed-beds are dry and without vegetation cover.

Although this study deals with booming site characteristics of males, several facts suggest that these results are representative of females' nesting sites. The bittern is a polygynous species and the major function of booming behaviour is considered to be territorial defence and mate attraction (Voisin, 1991). Boom train length has been shown to vary among individuals in the Camargue, and this costly behaviour is probably used by females as a cue to assess male and/or habitat quality (Poulin \& Lefebvre, 2003a). Systematic searches for nests at both sites revealed a total of 35 nests within the proximity $(<75 \mathrm{~m})$ of 24 booming males (L. Demongin, pers. comm.), confirming previous reports from Germany 
(Gauckler \& Kraus, 1965) and Italy (Puglisi et al., 2003), where booming and nesting sites overlap. Finally, no feeding flight has been detected in 60 hours of observation at various booming sites at Charnier-Scamandre during the nestling period (B. Poulin \& G. Lefebvre, pers. obs.), suggesting that most foraging activities are carried out at the proximity of booming, and nesting, sites.

The bittern is an eclectic species distributed over a wide geographical range that includes a diversity of potential breeding habitats. The assessment of the species' ecological requirements must rely on precise locations of the birds and be interpreted in relation to the gradient of environmental conditions available in each type of habitat used. This information is necessary to propose adequate management practices if the decline observed in many localities (Tucker \& Heath, 1994) is to be halted. The two most important factors involved in habitat selection by males in this study (water level and dry reed density) are directly associated with site management, and the comparison of the 2001 and 2002 data at Charnier-Scamandre demonstrates that bitterns can respond rapidly to slight modifications in environmental practices.

\section{Acknowledgements}

This study is part of the Reed-bed Programme of the Station Biologique de la Tour du Valat. Financial support was provided by the Fondation Sansouire, the Office Franco-Québécois pour la Jeunesse, and the European Commission (LIFE00 NAT/F/007269). We are indebted to Emilien Duborper, Karine Gauthier, Eric Gingras, Marianne Théberge, Alexandre Rivard, Marc-André Roy, Yoann Perrot, Paula Delgado and the équipe of the Marais du Vigueirat for their contribution to the field work. We are grateful to all the land owners and managers who gave us access to their reed-beds.

\section{References}

Akaike, H. (1973) Information theory and an extension of the maximum likelihood principle. In Proceedings of the 2 nd International Symposium on Inference Theory (eds B.N. Petran \& F. Csáki), pp. 267-281. Akadémiai Kiadi, Budapest, Hungary.

Alessandria, G., Carpegna, R. \& Toffola, M.D. (2003)

Vocalizations and courtship displays of the bittern Botaurus stellaris. Bird Study, 50, 182-184.

Bibby, C.J. \& Lunn, J. (1982) Conservation of reed-beds and their avifauna in England and Wales. Biological Conservation, 23, 167-186.

Burnham, K.P. \& Anderson, D.R. (2002) Model Selection and Multimodel Inference, A Practical Information-theoretic Approach. Springer-Verlag, New York, USA.

Cramp, S. \& Simmons, K.E.L. (1977) Handbook of the Birds of Europe, the Middle East and North Africa: The Birds of the Western Palearctic, Volume 1. Oxford University Press, Oxford, UK.
De Kroon, G.H.J. (2001) Reed bed quality and decline of some breeding bird populations. In The Ecology of Reedbed Birds. Biosystematics and Ecology Series No. 18 (ed. H. Hoi), pp. 37-46. Austrian Academy of Sciences, Vienna, Austria. Everitt, B.S. (1992) The Analysis of Contingency Tables. 2nd edition. Chapman \& Hall, London, UK.

Gauckler, A. \& Kraus, M. (1965) Zur brutbiologie der Grossen Rohrdommel (Botaurus stellaris). Vogelwarte, 86, 129-146.

Hawke, C.J. \& Jose, P.V. (1996) Reed-bed Management for Commercial and Wildlife Interests. RSPB, Sandy, UK.

Johnson, J.B. \& Omland, K.S. (2004) Model selection in ecology and evolution. Trends in Ecology and Evolution, 19, 101-108.

Keating, K.A. \& Cherry, S. (2004) Use and interpretation of logistic regression in habitat-selection studies. Journal of Wildlife Management, 68, 774-789.

Kushlan, J.A. \& Hafner, H. (2000) Heron Conservation. Academic Press, London, UK.

Lefebvre, G. \& Poulin, B. (2003) Accuracy of bittern location by acoustic triangulation. Journal of Field Ornithology, 74, 305-311.

Mathevet, R. (2001) Commercial value of reed and the impact of agro-environmental policies in the Rhone delta. In Wildlife, Land and People: Priorities for the 21st Century (eds R. Field, R.J. Warren, H. Okarma \& P.R. Sievert), pp. 389-393. The Wildlife Society, Bethesda, USA.

Mathevet, R., Mauchamp, A., Lifran, R., Poulin, B. \& Lefebvre, G. (2003) ReedSim: simulating ecological and economical dynamics of Mediterranean reed-beds. In Integrative Modelling of Biophysical, Social and Economic Systems for Resource Management Solutions (ed. D. Post), pp. 1007-1012. Modelling and Simulation Society of Australia and New Zealand Inc., Townsville, Australia.

Mathevet, R. \& Mesléard, F. (2002) The origins and functioning of the private wildfowling lease system in a major Mediterranean wetland: the Camargue (Rhone delta, southern France). Land Use Policy, 19, 277-286.

McCullagh, P. \& Nelder, J.A. (1999) Generalized Linear Models. 2nd edition. Chapman \& Hall, London, UK/CRC, Boca Raton, USA.

Poulin, B. \& Lefebvre, G. (2003a) Booming variations among great bitterns Botaurus stellaris in the Camargue. Ardea, 91, 177-181.

Poulin, B. \& Lefebvre, G. (2003b) Optimal sampling of booming bitterns Botaurus stellaris. Ornis fennica, 80, 11-20.

Poulin, B., Lefebvre, G. \& Mauchamp, A. (2002) Habitat requirements of passerines and reed-bed management in southern France. Biological Conservation, 107, 315-325.

Puglisi, L., Adamo, M.C. \& Baldaccini, N.E. (2003) Spatial behaviour of radio-tagged Eurasian bitterns Botaurus stellaris. Avian Science, 3, 133-143.

Rocamora, G. \& Yeatman-Berthelot, D. (1999) Oiseaux menacés et à surveiller en France. Listes rouges et recherche de priorités. Populations. Tendances. Menaces. Conservation. Société d'Études Ornithologiques de France (SEOF) and Ligue pour la Protection des Oiseaux, Paris, France.

Tucker, G.M. \& Heath, M.F. (1994) Birds in Europe: Their Conservation Status. Birdlife International (Birdlife Conservation Series No. 3), Cambridge, UK.

Tyler, G.A. (1992) Reed-beds, their wildlife and requirements. B. Requirements of birds in reed-beds. In Reed-beds for Wildlife (ed. D. Ward), pp. 57-64. RSPB and University of Bristol Information Press, Oxford, UK.

Tyler, G.A., Smith, K.W. \& Burges, D.J. (1998) Reed-bed management and breeding bitterns Botaurus stellaris in the UK. Biological Conservation, 86, 257-266. 
Voisin, C. (1991) The Herons of Europe. Poyser, London, UK Ward, D. (1992) Management of reed-beds for wildlife. In Reedbeds for Wildlife (ed. D. Ward), pp 65-78. RSPB, University of Bristol Information Press, Oxford, UK. White, G.C. \& Garrott, R.A. (1990) Analysis of Wildlife Radio-tracking Data. Academic Press, New York, USA.

\section{Biographical sketches}

Brigitte Poulin and Gaëtan Lefebvre have previously worked on the phenology and niche segregation of birds in various neotropical habitats, with particular emphasis on trophic relationships and food availability assessment. Since 1996 they have been involved in a multidisciplinary project on the management and conservation of Mediterranean reedbeds that integrates plant and animal ecology with geography and social sciences. The goal is to find the best compromise between the short-term requirements of vulnerable species and those of socio-economic users to ensure the long-term health of the reed marsh ecosystem.

Raphaël Mathevet has research interests in wetland management and social-ecological interactions. His work addresses Mediterranean wetland uses to develop management plans that combine nature conservation and issues associated with human activities. 